\title{
A TECHNIQUE FOR MEASURING REGIONAL MYOCARDIAL BLOOD FLOW AND ITS APPLICATION IN DETERMINING THE EFFECTS OF HYPERVENTILATION AND HALOTHANE
}

\author{
M. Marshall, W.G. Whlliams, R.E. Creighton, G.A. Volgyesi, \\ AND D.J. STEWARD
}

IsCHAEMIC DAMAGE of the subendocardial region of the wall of the left ventricle is a common finding in patients who die after cardiac surgery. Some factors that influence the distribution of blood flow within the myocardium have been determined, ${ }^{1-4}$ but little is known of the effects of anaesthetic drugs and techniques.

This paper describes a method for determining regional myocardial blood flow and its application in experiments to determine the effects of halothane and respiratory alkalosis on blood flow to the subendocardium and subepicardium.

\section{Materials AND Methods}

Regional blood flow was determined by a modified polarographic hydrogen clearance technique (Figure 1). In the presence of a platinum electrode, hydrogen combines with oxygen to form water in an electrochemical reaction. The electrons travelling through an external circuit constitute a small electric current of a magnitude proportional to the hydrogen concentration at the electrode. Small concentrations of hydrogen added to inspired air are distributed throughout the body tissues and are detected by implanted platinum electrodes. On withdrawal of the hydrogen, a washout curve is obtained which reflects blood flow to adjacent tissue (Figure 2).

Myocardial blood flows were calculated from these hydrogen clearance curves. The half time ( $t / 2)$ was measured from a semi-logarithmic plot of hydrogen concentration with time. The flow was then calculated using the formula:

$$
\text { flow }=0.693 \div t / 2^{5,6}
$$

The tissue/blood solubility coefficient for hydrogen was assumed to be 1.0. ${ }^{\mathrm{n}}$

\section{Manufacture and Insertion of Electrodes}

The electrodes were made from Teflon-coated multistrand, stainless-steel pacemaker wire (Flexon 2597-63; American Cyanamid Co., Pearl River, N.Y.). Near the end to be implanted, $1 \mathrm{~mm}$ of the Teflon coating was removed and the exposed area was tightly wrapped with 36 -gauge stainless-steel wire. This wire-wrapped portion of the electrode was electroplated by brief immersion in 5 per cent platinic

From the Departments of Anaesthesia \& Cardiovascular Surgery, The Hospital for Sick Children, and The University of Toronto, Toronto, Ontario.

Mailing Address: Dr. D.J. Steward, Room 2304, Hospital for Sick Children, 555 University Avenue, Toronto, Ontario M5G 1 X8. 


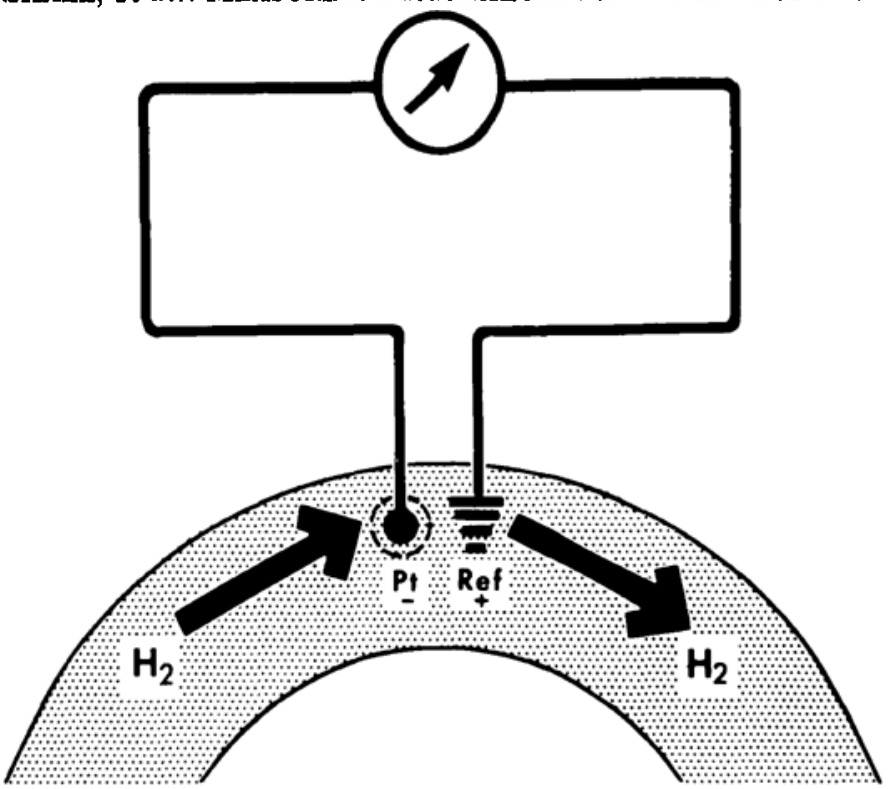

\section{$2 \mathrm{H}_{2}+\mathrm{O}_{2} \rightarrow 2 \mathrm{H}_{2} \mathrm{O}+\overline{\mathrm{e}}$}

FIGURE 1. The electrochemical reaction at the hydrogen electrode.

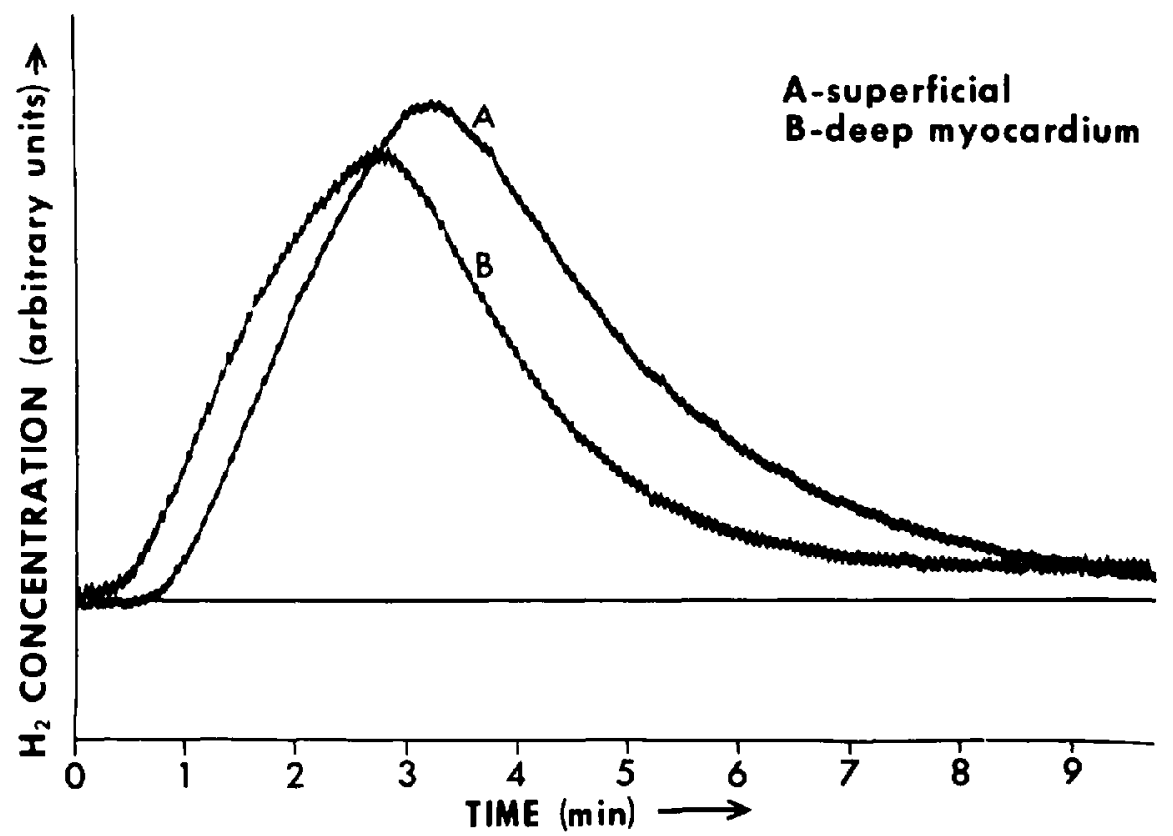

Figure 2. Hydrogen washout curves from which myocardial blood flow is calculated.

chloride solution, using a voltage of 1.5. Only a very light plating was needed to produce sensitive and stable electrodes.

The electrodes were sterilized and were surgically implanted in the left ventricular myocardium. A reference electrode was placed adjacent to each active electrode 


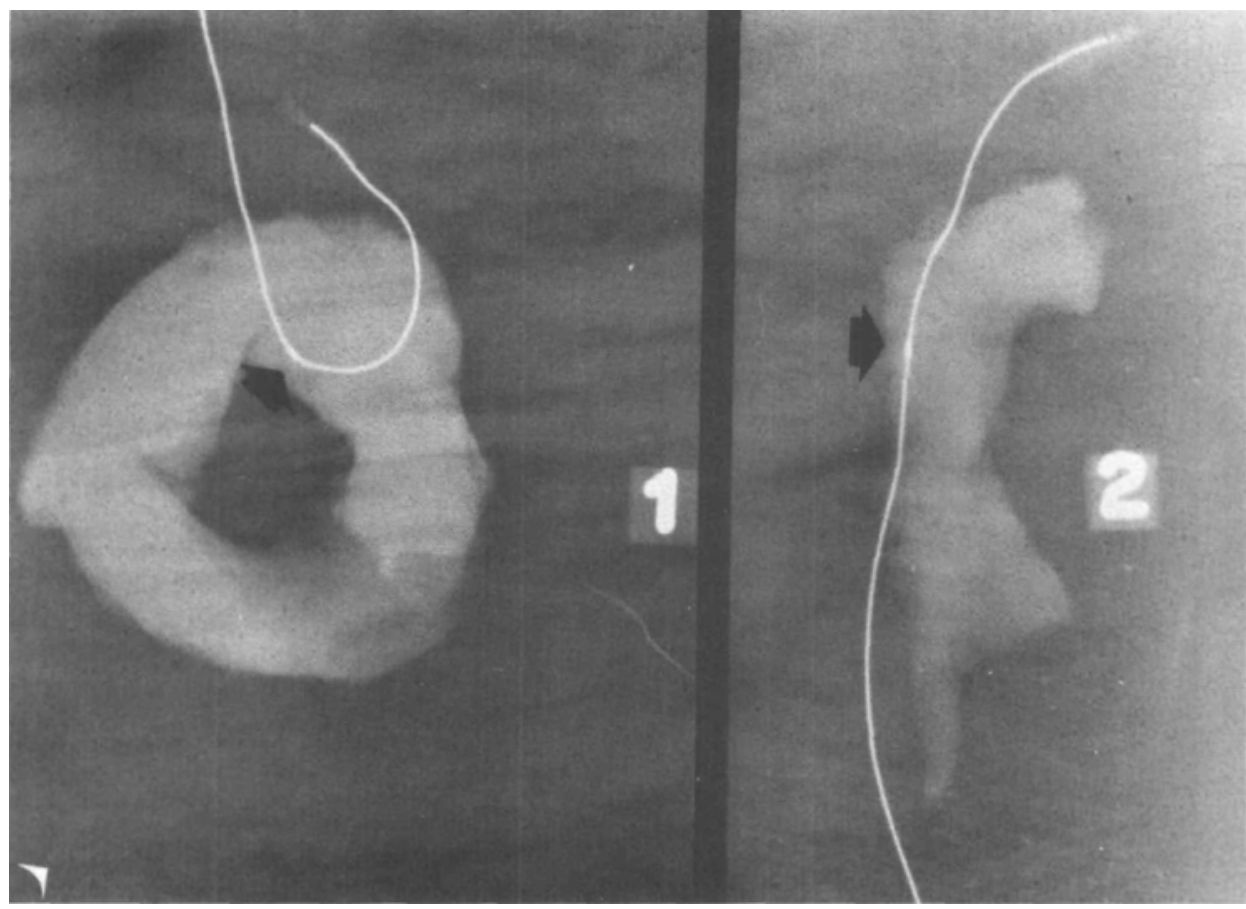

Figure 3. Radiographs of slice of dog myocardium showing position of deep and superficial electrodes. The arrows indicate the platinized area.

to reduce mutual interference by their electric fields and to minimize the amplitude of the ECG signal received, thus increasing the signal:noise ratio. One pair of electrodes was placed in the superficial layer of the myocardium $(3 \mathrm{~mm})$, and the other pair in the deep layer $(8 \mathrm{~mm})$. The proximal ends of the electrodes were enclosed in a small Teflon capsule and placed in a subcutaneous pouch, for easy retrieval without opening the chest at the start of each experiment.

At the end of the series of experiments the dogs were sacrificed. The heart was removed and sliced and relevant areas were radiographed to confirm the position of the electrodes (Figure 3).

\section{Experimental Procedure ( figure 4)}

In each dog, the first experiment was done at least two weeks after insertion of the electrodes. The dog was anaesthetized, intubated, and ventilated with air, using a Volgyesi ventilator. ${ }^{7}$ The dog was placed on a warming blanket and its rectal temperature was monitored with a thermister probe. Tidal volume was maintained constant and the frequency was varied to produce normocarbia $\left\langle\mathrm{Pa}_{\mathrm{CO}_{2}}=37 \mathrm{~mm} \mathrm{Hg}\right.$ ) or hypocarbia $\left(\mathrm{Pa}_{\mathrm{CO}_{2}}=23 \mathrm{~mm} \mathrm{Hg}\right.$ ), confirmed by frequent blood-gas studies. Catheters were inserted into the aorta through the femoral artery and into the right atrium through a peripheral vein. The electrocardiogram (ECG), aortic blood pressure curve, mean aortic blood pressure (MABP), and right atrial pressure (RAP) were recorded on a Beckman Dynograph recorder, 


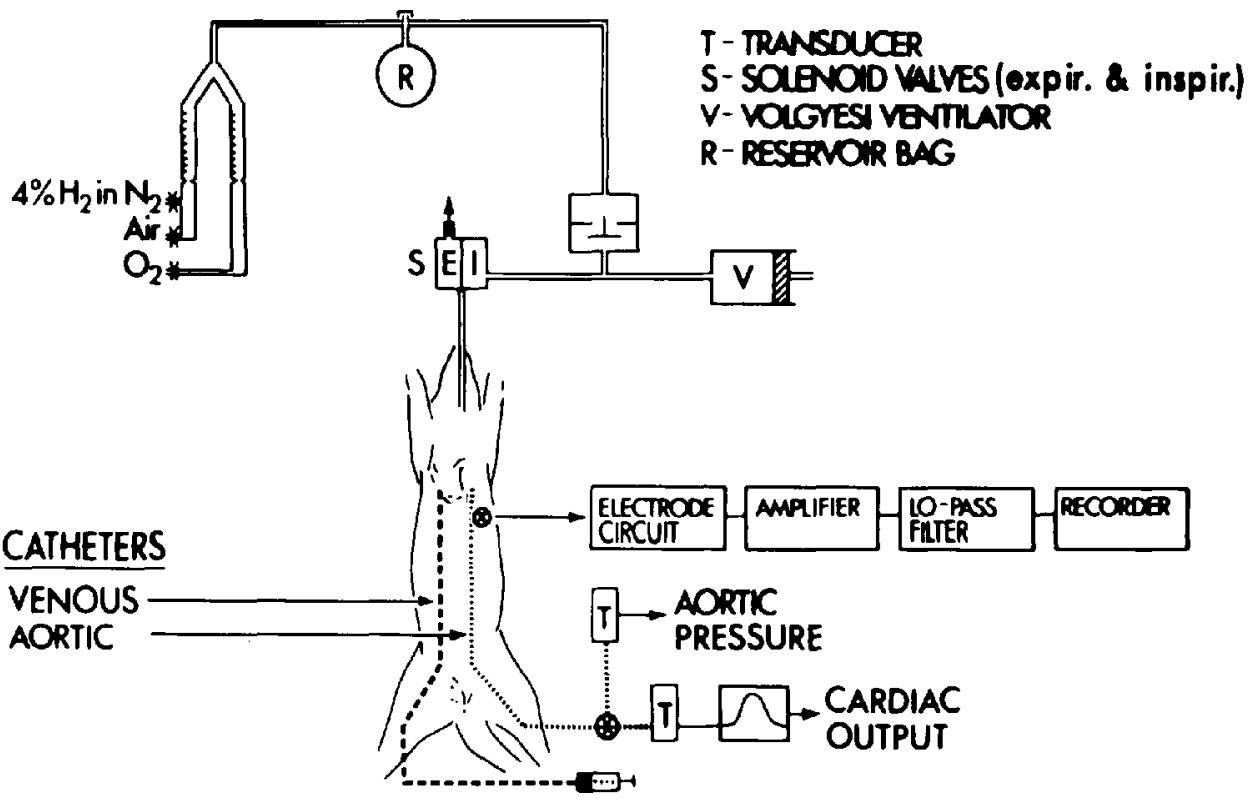

FIGURE 4. Schematic representation of experiment.

model RM. Cardiac output was measured by an indicator-dilution technique, using indocyanine green dye.

The hydrogen electrode wires were recovered from the subcutaneous pouch and attached to a sterilized terminal block. The electric signal from the electrodes, produced in the presence of $\mathrm{H}_{2}$, was processed through an amplifier and a low-pass filter ${ }^{*}$ to remove the superimposed ECG signal, and recorded on a strip chart recorder.

For measurement of myocardial blood flow (MBF), the air was turned off and the dog was ventilated with a mixture of 4 per cent hydrogen, 21 per cent oxygen, with nitrogen to 100 per cent. Hydrogen washout curves were plotted from the point of which air was substituted for the ventilating mixture. To ensure smooth curves and a stable base line, no other measurements were taken during this time.

Heart rate, MABP, cardiac output, and subepicardial and subendocardial blood flow were measured during both pentobarbitone anaesthesia and 0.5 per cent halothane administration. Each experiment was repeated at the two arterial $\mathrm{CO}_{2}$ tensions. Myocardial vascular resistance (MVR) was calculated from the formula: MVR $=($ MABP - RAP $) / M B F$.

A total of seven experiments were performed, and the results were analyzed with the paired t-test.

\section{Results}

Hyperventilation during pentobarbitone anaesthesia was followed by a fall in cardiac output and in both superficial and deep myocardial blood flow, but did not

'The circuit diagram is available on request, from Mr. G. Volgyesi, Rm 2220, The Hospital for Sick Children, 555 University Avenue, Toronto, Ontario, M5G IX8. 
alter heart rate or mean aortic pressures (Table $1 \mathrm{~B}$ ); myocardial vascular resistance (Table II B) was significantly increased at both superficial and deep levels.

The addition of 0.5 per cent halothane decreased cardiac output and myocardial blood flows (Table I C) but did not significantly alter MVR (Table II C).

As will be seen from Table I $\mathrm{D}$, hyperventilation combined with halothane $\left(\mathrm{Pa}_{\mathrm{CO}_{2}}=22 \mathrm{~mm} \mathrm{Hg}\right.$ ) caused the greatest decrease in flow to both superficial and deep areas of the myocardium; however, MVR did not significantly change (Table II D).

The ratio between deep and superficial flows did not alter significantly during hyperventilation or halothane administration.

\section{Discussion}

The method described for measuring regional myocardial blood flow has several advantages. With it, one can measure blood flow to a discrete area and can repeat these measurements many times, permitting investigation of changes in the distribution of total coronary blood flow within the left ventricular wall. It should be noted, however, that this method measures the average flow during systole and diastole over a period of several minutes.

Under control conditions during pentobarbitone anaesthesia there was no significant difference in blood flow to superficial and deep areas of the left ventricle. Several authors ${ }^{1-3}$ have reported this uniformity of flow, but at least one group ${ }^{4}$ has described differences between deep and superficial myocardial blood flows.

We could find no reports in the literature of the effects of hyperventilation on the distribution of myocardial blood flow although a fall of approximately 20 per cent in total myocardial blood flow induced by hyperventilation and similar falls in total coronary blood flow, ${ }_{9}^{9.10}$ have been described. The present experiments indicate that the decrease in blood flow to the myocardium during hyperventilation is uniform in the regions measured, namely, the subendocardium and subepicardium, and that this decrease in flow is associated with an increase in MVR at both levels.

The addition of 0.5 per cent halothane decreased cardiac output and uniformly decreased deep and superficial myocardial blood flow approximating reported halothane-induced changes in total myocardial blood flows. ${ }^{11}$ MVR in both regions of the myocardium showed a slight, insignificant rise, as has been observed by others. ${ }^{11,12}$ The fall in myocardial blood flow with halothane is probably secondary to the known decrease in both cardiac output and myocardial oxygen consumption during inhalation of this agent. Hyperventilation with 0.5 per cent halothane caused the greatest fall in both superficial and deep myocardial blood flow (approximately 30 per cent) and in cardiac output, but was not associated with significant changes in myocardial vascular resistance.

These experiments demonstrate that neither low concentrations of halothane nor respiratory alkalosis alter the distribution of myocardial blood flow under the conditions of the study. The observed effects of hyperventilation on myocardial blood flow and myocardial vascular resistance suggest that respiratory alkalosis may have adverse effects on myocardial perfusion during clinical anaesthesia. 


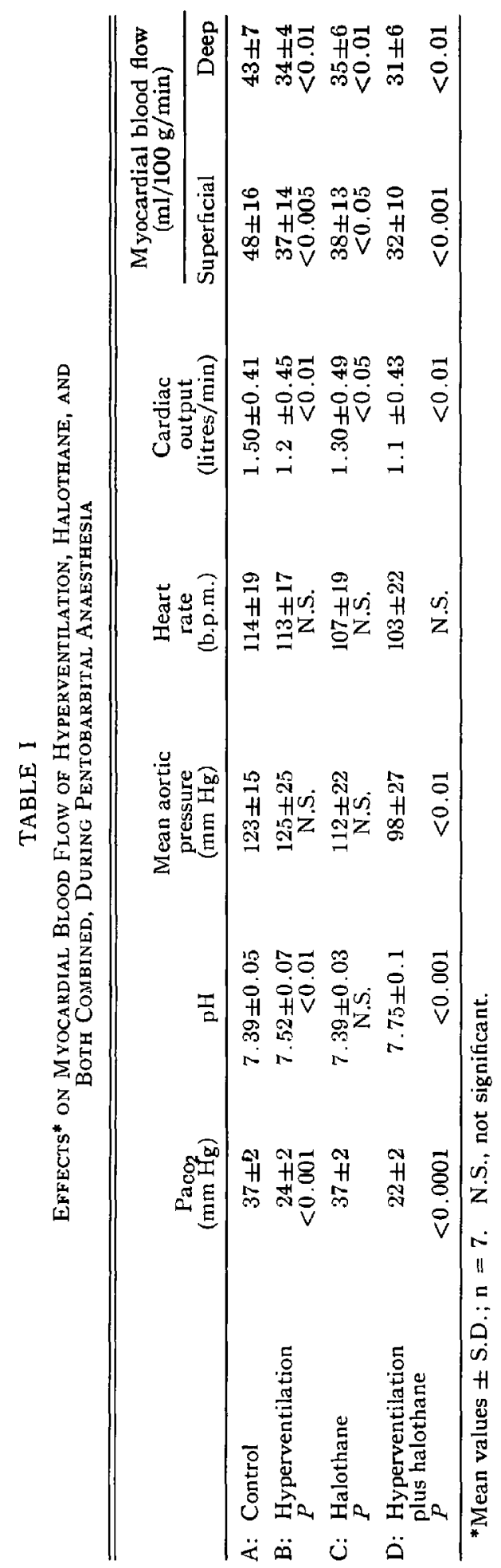


TABLE II

EFfects* on Myocardial Vascular Resistance (MVR) of Hyperventilation, Halothane (0.5 PER CENT), and Both Combined, During Pentobarbital Anaesthesia

\begin{tabular}{|c|c|c|c|}
\hline & \multirow{2}{*}{$\underset{(\mathrm{mm} \mathrm{Hg})}{\mathrm{Paco}_{2}}$} & \multicolumn{2}{|c|}{ MVR (units) } \\
\hline & & Superficial & Deep \\
\hline \multirow{6}{*}{$\begin{array}{l}\text { A: Control } \\
\text { B: Hyperventilation } \\
\\
\text { C: Halothane } \\
\\
\text { D: Hyperventilation } \\
\\
\quad \begin{array}{l}P \\
P\end{array}\end{array}$} & $37 \pm 2$ & 2.35 & 2.63 \\
\hline & $24 \pm 2$ & 3.11 & $\begin{array}{r}3.38 \\
<0.005\end{array}$ \\
\hline & $37 \pm 2$ & 2.68 & $\begin{array}{l}2.91 \\
2.91\end{array}$ \\
\hline & N.S. & N.S. & N.S. \\
\hline & $22 \pm 2$ & 2.78 & 3.14 \\
\hline & $<0.0001$ & N.S. & N.S. \\
\hline
\end{tabular}

${ }^{*}$ Mean values \pm S.D. $n=7$. N.S. = not significant.

\section{SUMMARY}

A method for measuring regional myocardial blood flow with a polarographic hydrogen-clearance technique, and its experimental application in dogs, are described. Under pentobarbitone anaesthesia, flow to the superficial $(3 \mathrm{~mm})$ and deep $(8 \mathrm{~mm})$ layers of the left ventricle was not significantly different. Neither hypocapnia $\left(\mathrm{Pa}_{\mathrm{CO}_{2}}=24 \mathrm{~mm} \mathrm{Hg}\right)$ nor halothane significantly altered differential distribution of blood flow to the superficial and deep layers of the myocardium. Hypocapnia was followed by a fall in myocardial blood flow (MBF) associated with increased myocardial vascular resistance (MVR).

Administration of halothane 0.5 per cent at normal levels of $\mathrm{Pa}_{\mathrm{CO}_{2}}$ led to a fall in MBF of approximately 20 per cent with no significant changes in MVR.

\section{RésuMÉ}

Ce travail décrit une méthode de mesure du flot sanguin régional du myocarde par une technique polarographique de l'élimination de l'hydrogène et son utilisation expérimentale chez le chien.

Sous anesthésie au Pentobarbital, les débits sanguins mesurés dans les couches superficielle $(3 \mathrm{~mm})$ et profonde $(8 \mathrm{~mm})$ de la paroi du ventricule gauche n'ont montré que des différences insignifiantes.

Ni l'hypocapnie ( $\mathrm{Pa}_{\mathrm{CO}_{2}}=24 \mathrm{~mm} \mathrm{Hg}$ ) ni l'Halothane n'ont modifié de façon sensible la distribution du débit aux couches superficielle et profonde du myocarde. L'hypocapnie a entraîné une chute du débit sanguin myocardique accompagnée d'une augmentation de la résistance vasculaire.

Sous des conditions d'eucapnie, l'administration d'Halothane ( 0.5 pour cent) réduit le flot sanguin myocardique d'environ 20 pour cent sans changement sensible de la résistance vasculaire.

\section{REFERENCES}

1. Gross, G.J. \& Winbury, M.M. Beta adrenergic blockade on intranyocardial distribution of coronary blood flow. J. Pharmacol. Exp. Ther. 187: 451-464 (1973). 
2. Buckrerg, G.D. \& Ross, G. Effects of isoprenaline on coronary blood flow: its distribution and myocardial performance. Cardiovasc. Res. $7: 429-437$ (1973)

3. Buckuerg, G.D., Fixler, D.E., Anchie, J.P., \& Hoffman, J.I.E. Experimental subendocardial ischemia in dogs with normal coronary arteries. Circ. Res. 30: 67-81 (1972)

4. KIRK, E.S. \& Honig, C.R. Nonuniform distribution of blood flow and gradients of oxygen tension within the heart. Am. J. Physiol. 207: 661-668 (1964).

5. KETY, S.S. The theory and applications of the exchange of inert gas at the lungs and tissues. Pharmacol. Rev, 3: 1-41 (1951).

6. Aukland, K., Boweh, B.E., \& Berliner, R.W. Measurement of local blood flow with hydrogen gas. Circ. Res. 14: 164-187 (1964).

7. Volgyesi, G.A. \& NisBet, H.I.A. A new piston ventilator for use in respiratory studies. Can. Anaesth. Soc. J. 19: 662-669 (1972).

8. Vance, J.P., Crown, D.M., \& SMIth, G. The effects of hypocapnia on myocardial blood flow and metabolism. Br. J. Anaesth. 45: 455-463 (1973).

9. McArthur, W.J. Coronary flow response to hypocapnia induced by hyperventilation. Aerosp. Med. 36: 5-8 (1965).

10. Feinberg, H., Gerola, A., \& Katz, L.M. Effect of changes in blood CO, levels on coronary flow and myocardial $\mathrm{O}_{2}$ consumption. Am. J. Physiol. 199: 349-354 (19760).

11. Smith, G., VAnCe, J.P., Brown, D.M., \& MCMillan, J.C. Changes in canine myocardial blood How and oxygen consumption in response to halothane. Br. J. Anaesth. 46: 821-826 (1974).

12. Wolff, G., Claudi, B., Rist, M., Wardak, M.R., Niederen, W., \& Graedel, E. Regulation of coronary blood flow during ether and halothane anaesthesia. Br. J. Anaesth, 44: $1139-1149$ (1972). 